\title{
LA REGULACIÓN DEL SECTOR PÚBLICO INSTITUCIONAL EN EL PROYECTO DE LEY DE RÉGIMEN JURÍDICO DEL SECTOR PÚBLICO
}

\author{
Miguel Sánchez Morón \\ Catedrático de Derecho Administrativo \\ Universidad de Alcalá \\ miguel.sanchez@uah.es
}

I

El objeto de esta ponencia es comentar los preceptos que se dedican al llamado "sector público institucional" en el Proyecto de Ley de Régimen Jurídico del Sector Público presentado en Las Cortes en el mes de mayo de 2015. Antes de entrar en materia, conviene exponer algunas breves observaciones introductorias.

La finalidad del citado Proyecto de Ley y, muy en especial, la regulación que en él se contiene del sector público institucional, es contribuir a la reforma administrativa impulsada por el Gobierno desde el año 2012, cuya responsabilidad directa se atribuyó a la Comisión para la Reforma de las Administraciones Públicas (CORA). La reforma propuesta por esta Comisión, que se sustenta en los principios de eficacia y eficiencia administrativas y en los de estabilidad presupuestaria y sostenibilidad financiera, tiene en ese aspecto -el del sector público institucional- uno de sus objetivos esenciales, tal como se deduce de la extensión que a él se dedica en el Informe de la CORA publicado en 2013. Lo que con ello se pretende es, en sustancia, una simplificación y racionalización de la estructura del sector público institucional del Estado, a lo que se añaden algunas novedades -no muchas, a decir verdad-sobre su funcionamiento. La Comisión realizó al efecto un minucioso trabajo de análisis de los entes instrumentales existentes en el sector público estatal y propuso la supresión, fusión o transformación de un buen número de ellos, lo que en parte se ha llevado ya a término.

Sin duda este objetivo es loable y no sólo en lo que afecta al sector público estatal, sino también al de Comunidades Autónomas y Administración Local, pues en los últimos decenios se ha venido creando, por unas u otras causas -no todas igualmente justificadas-, un número muy elevado de entidades públicas instrumentales de todo tipo.

Basta para confirmarlo con tener en cuenta los datos que aparecen en el Inventario de Entidades del Sector Público, que publica la IGAE, y que comprende todos los entes de esta naturaleza en los tres niveles territoriales de Administración. Aunque la página web advierte que el Inventario está en proceso de actualización, en el mes de junio de 2015 se incluyen en el mismo nada menos que 18.863 entidades, clasificadas en cerca de veinte categorías distintas. Cierto que la mayoría de ellas son Entidades Locales: municipios, entidades locales menores, mancomunidades, comarcas, otras agrupaciones de municipios, diputaciones provinciales y entidades insulares. Pero en lo que se puede considerar el "sector público institucional", tal como lo denomina el Proyecto de Ley que ahora comentamos, se cuentan más de 5.600 entes de diferente naturaleza y así: 1.377 organismos autónomos y agencias, 94 entidades públicas empresariales, 2.238 sociedades mercantiles del sector público, 852 fundaciones públicas, 863 consorcios y otros 220 entes públicos de variadas denominaciones.

Admitamos que no son todos los que están. Parece que hace tiempo que el Inventario no se actualiza y de hecho incluye entidades que ya se han extinguido por ley o por decreto o se han fusionado con otras en los últimos tiempos. Ha habido, bien es cierto, un largo proceso de reordenación del sector público tanto en el ámbito del Estado como en el de las Comunidades Autónomas y la Administración Local, que se inició ya en el año 2010 con el Acuerdo 1/2010, de 22 de marzo, del Consejo de Política Fiscal y Financiera sobre sostenibilidad de las finanzas públicas y que ha seguido más tarde, si cabe con mayor vigor, en aplicación de los planes de ajuste y reequilibrio que impuso la Ley Orgánica de Estabilidad Presupuestaria y Sostenibilidad Financiera en 2012, y en virtud de políticas de racionalización administrativa impulsadas por el Gobierno del Estado y por diferentes gobiernos autonómicos 
y locales ${ }^{1}$. Así, según el último informe de seguimiento de la reforma administrativa hecho público por la CORA², hasta el mes de mayo de 2015 se habrían suprimido 2.194 entidades de diferente naturaleza, a saber 105 de ámbito estatal, 715 dependientes de las Comunidades Autónomas y 1.374 en el ámbito local. No se señala en ese informe, sin embargo, cuál es la fecha de inicio de este cómputo ni se ofrecen mayores detalles para contrastar su rigor. Pero debe darse por bueno que hay entes incluidos en el Inventario de la IGAE que ya no existen o están en fase de liquidación. Por el contrario, es posible que tampoco estén (en el Inventario) todos los que son, como sugiere el hecho de que el propio Proyecto de Ley que comentamos se preocupe de que todas las Administraciones remitan información completa sobre las entidades de su propio sector institucional para inventariarlas y recoja alguna medida compulsiva al respecto, en los términos que diremos.

En todo caso, son muchas las entidades del sector público. Y precisamente por ello y en atención a lo dispuesto en el artículo 135 de la Constitución, lo que el Proyecto de Ley pretende es una mejor ordenación de todo ese sector institucional, aumentar los controles y, sobre todo, reducir y limitar su volumen o extensión. Propósito que también es elogiable, aunque podía y debería haberse complementado, en una norma de tanta importancia y alcance general, con otras previsiones tendentes a mejorar el funcionamiento interno de las entidades que en cada momento existan.

Ahora bien, una cosa es que la finalidad del Proyecto de Ley en este aspecto deba valorarse positivamente y otra distinta cómo pretende llevarse a cabo, es decir, si lo que expresan las normas contenidas en el Proyecto de Ley es coherente con aquel objetivo y permite conseguirlo de manera satisfactoria. En otros términos, lo que hay que analizar es si los redactores del texto aciertan o no al ordenar el sector público institucional. Y esto es ya mucho más discutible. Pues, junto a algunas novedades de interés, dignas de aplauso, el texto del Proyecto de Ley enviado a Las Cortes incurre en no pocos defectos jurídicos o, si se prefiere, de técnica legislativa, que de no corregirse podrían plantear nuevos problemas de interpretación y aplicación de la Ley, en el caso de que llegara a aprobarse. Y, como sucede en algunos casos -de los que puede ser buen ejemplo la reciente Ley de Racionalización y Sostenibilidad de la Administración Local de 27 de diciembre de 2013- tales problemas pueden mermar la eficacia de la propia Ley o tener consecuencias distintas de las pretendidas y poco previsibles.

Legislar, además del ejercicio de un Poder del Estado y un acto de voluntad política, es también un arte, que no todos dominan. Los principios en que se basa, sancionados hoy en protocolos o en normas legales -véase el artículo 4 de la Ley de Economía Sostenible- se resumen en realidad en tres: las leyes deben ser necesarias, claras y bien estructuradas. Y para alcanzar estos objetivos, al menos las revisiones de los textos legales fundamentales requieren un estudio muy meditado, no poca prudencia y el consejo de expertos, comisiones y órganos consultivos. Casi nada de esto parece haberse procurado en la elaboración del Proyecto de Ley de Régimen Jurídico del Sector Público, como en el paralelo Proyecto de Ley del Procedimiento Administrativo Común de las Administraciones Públicas (título este redundante). Tan solo a su fin se ha consultado de urgencia al Consejo de Estado, cuyo informe ${ }^{3}$ es muy crítico y, sintomáticamente, no se ha tenido demasiado en cuenta por el Gobierno. Y es que cabe dudar muy seriamente de que esas dos iniciativas -que restructuran por entero dos de las leyes básicas de nuestro Derecho administrativo- fueran necesarias, ya que en realidad innovan muy poco y sus novedades podrían muy bien haberse articulado como reformas parciales de los textos vigentes. Tampoco ofrecen la necesaria claridad en sus preceptos, sino que, como se verá más adelante en la materia que tratamos (al igual que en otras muchas), adolecen de graves imprecisiones y oscuridades. Y ello por no hablar de la incomprensible sistemática que se ha seguido, defecto éste que el Consejo de Estado ha resaltado meridianamente en su dictamen.

En concreto, el Proyecto de Ley de Régimen Jurídico del Sector Público yuxtapone, con no demasiado orden, normas que tienen carácter básico y otras -la mayoría- que no lo tienen; normas sobre la organización de las Administraciones y entes públicos y sus relaciones y otras sobre su actividad. Inclusive hay en él algunas normas que atañen más bien al procedimiento administrativo, como las que regulan la abstención y la recusación. No se entiende tampoco por qué recoge algunas normas sobre sobre el "funcionamiento electrónico del sector público", cuando la mayoría de las que regulan la llamada administración electrónica se hallan en el Proyecto de Ley del Procedimiento Administrativo Común. Menos lógica tiene aún que se hayan escindido y regulado por separado en ambos Proyectos de Ley las normas sobre sanciones administrativas y responsabilidad civil de la Administración. En fin y para no apurar este tipo de crítica, resulta chocante que los convenios no se regulen en el Título III del Proyecto de Ley, relativo a las "relaciones interadministrativas", cuando son una de las formas más comunes mediante las que se establecen estas relaciones.

1 Véase sobre ello el “Informe sobre el impacto del sector público autonómico en la actividad económico-financiera de las Comunidades Autónomas”, MINHAP, Secretaría General de Coordinación Autonómica y Local, 2014.

2 "Informe trimestral de seguimiento de las medidas de la Comisión para la reforma de las Administraciones Públicas", marzo de 2015. Disponible en www.mihap.gob.es/es/areas/reforma aapp.htlm.

3 Dictamen 274/2015, de 29 de abril. 
Las reformas de la legislación del régimen jurídico administrativo de los años 90, también criticables en ciertos aspectos -y muy criticadas en su día-, diferenciaban al menos la legislación básica o de competencia exclusiva estatal pero aplicables a todas las Administraciones, contenidas en la Ley 30/1992, relativa a la actividad y al procedimiento administrativos, de la legislación no básica y referida a la organización administrativa, contenida en la LOFAGE, complementada ésta por la Ley del Gobierno. Ese era un esquema mucho más claro y sencillo. Podía quizá mejorarse, pues la Ley 30/1992 contiene también algunas normas -pocas- no básicas sobre la organización administrativa. Pero, como el Consejo de Estado ha resaltado ya en su informe sobre los dos nuevos Proyectos de Ley, carece de sentido mezclar unas cosas y otras, lo que se hace en ciertos casos se diría que sin ton ni son, en ambos Proyectos, sobre todo en el de la Ley de Régimen Jurídico del Sector Público.

\section{II}

Pero pasemos ya a examinar qué dispone este último Proyecto sobre el "sector público institucional", concepto este, por cierto, que recupera una terminología tradicional y en el que se comprende -matices parte- el conjunto de entidades con personalidad jurídica propia que dependen o están vinculadas orgánicamente a las Administraciones territoriales.

Al sector público institucional dedica el Proyecto de Ley el Título II, más algunas disposiciones adicionales. Sin embargo, no hay en este Título una definición precisa de ese concepto, de carácter básico y válida para todos los niveles de gobierno y administración, pues el Proyecto se limita a establecer en el artículo 84 la composición del sector público institucional estatal, que, por cierto, incluye los fondos sin personalidad jurídica, es decir, un tipo de estructura que no constituye entidad pública y tiene más que nada relieve a efectos presupuestarios.

Esa ausencia de definición general contrasta con la inclusión en el Proyecto de algunas normas básicas aplicables al sector público institucional del Estado, de las Comunidades Autónomas y de las Entidades Locales. Pero la aplicación de estas normas básicas y su alcance plantea alguna incertidumbre a priori, dado que las Comunidades Autónomas pueden definir con competencia plena lo que consideran su propio sector público. No deja de ser Ilamativo que el Estado organice, según el Proyecto de Ley, un Inventario del Sector Público Estatal, Autonómico y Local, con la pretensión de integrar en él, a efectos informativos, "todas las entidades integrantes del sector público institucional”, cuando cada Comunidad Autónoma puede disponer libremente qué entidades propias lo componen.

En realidad, los redactores del Proyecto de Ley parecen haber topado con un primer problema, de no fácil solución: ¿qué puede considerarse básico en esta materia organizativa? Muy poco, ya que la organización de las propias instituciones, incluida la propia Administración y su sector público institucional, es la "más genuina expresión" de la autonomía de las Comunidades, tal como destaca el Tribunal Constitucional (SSTC 76/1983, 14/1986 y 227/1988, por ejemplo), de manera que las normas básicas que condicionen el ejercicio de la autonomía en tal materia no pueden ser sino rigurosamente excepcionales y solo se justifican si existe un interés general o estatal prioritario.

Las normas básicas que se incluyen en el Proyecto de Ley son, por ello, escasas y se limitan a imponer a todas las Administraciones Públicas el deber de realizar una "supervisión continua" de todas "sus entidades dependientes" (aparte de reiterar los habituales principios de legalidad, eficiencia, estabilidad presupuestaria, transparencia y la obligación de atenerse a las previsiones anuales de los presupuestos generales -falta decir "del Estado"- en materia de personal), así como la obligación de remitir la información necesaria para el Inventario del Sector Público Estatal, Autonómico y Local.

Sin entrar ahora en mayores detalles, ambas normas pueden ser aceptadas como básicas, por diferentes razones. En cuanto al deber de supervisión continua, cuya finalidad es determinar qué entidades deben mantenerse, transformarse o extinguirse (art. 81.2), encuentra sus justificación en el principio constitucional de estabilidad presupuestaria y sostenibilidad financiera (art. $135 \mathrm{CE}$ ), ya que es un medio o instrumento para asegurar su efectividad. Por otra parte, el Proyecto de Ley no pretende concretar ese deber con normas de detalle para las Comunidades Autónomas y solo lo desarrolla para el sector público estatal (art. 85), de manera que cada Comunidad Autónoma podría decidir en ejercicio de su autonomía cómo y cuándo realizarlo.

Por lo que se refiere a la obligación de remitir la información necesaria para confeccionar y actualizar el Inventario del Sector Público (art. 82), se justifica como un deber de colaboración administrativa, cuyo objetivo es conocer la dimensión y características del mismo, al objeto de poder adoptar las políticas que correspondan, en su caso mediante acuerdos o convenios o en el marco del Consejo de Política Fiscal y Financiera y otros órganos de cooperación. Además, la información integrada en el Inventario puede ser necesaria para su transmisión a las instituciones de la Unión Europea y a otros organismos internacionales que la requieran. Ello no obstante, el Proyecto 
de Ley se extiende a algunas reglas de detalle sobre la forma de remitir esa información (art. 83), que parecen más propias de una regulación reglamentaria.

Aparte de ello, lo básico se limita a la regulación de los consorcios y a dos artículos referidos a las fundaciones del sector público. Sobre los consorcios, el carácter básico de las normas se explica porque se trata de entes de cooperación entre Administraciones, en los que puede participar el Estado y, más frecuentemente, las Administraciones Locales, a las que el Estado puede extender su legislación básica en virtud del consabido "carácter bifronte" del régimen local. Pero, como ha señalado el Consejo de Estado, se debería haber previsto que dicha legislación no es aplicable a consorcios constituidos exclusivamente por Comunidades Autónomas o por éstas y otras entidades del propio sector público institucional.

En cualquier caso, la regulación básica mínima contenida en el Proyecto de Ley, debería haberse completado con una definición general del sector público institucional, lo suficientemente abierta para no invadir las competencias autonómicas, pero necesaria para que se entienda a qué entidades se refiere aquella regulación básica. Habría bastado con referirse, por ejemplo, a todas aquellas entidades de derecho público o privado que dependan efectivamente de la Administración autonómica correspondiente o estén orgánicamente vinculadas a ella, sin perjuicio de su independencia funcional. Incluso hubiera sido posible remitirse a lo que, en aplicación del Derecho europeo, disponen ya otras leyes, en particular el artículo 3 de la Ley de Contratos del Sector Público.

III

Por lo que se refiere al sector público institucional del Estado, la finalidad primera del Proyecto de Ley es refundir en un solo texto legal las normas hoy dispersas en varios, que se refieren a la misma materia o a algunas de las entidades. En la Exposición de Motivos que acompaña al Proyecto se hace recuento de esta dispersión normativa, aunque sin explicar demasiado las razones que la han originado. Es cierto, de todas formas, que las normas legales sobre ese sector público institucional se encuentran hoy en la LOFAGE, en la Ley General Presupuestaria, en la Ley de Agencias Estatales, en la Ley de Patrimonio de las Administraciones Públicas -por lo que se refiere a las sociedades y algo a las entidades públicas empresariales- en algunos artículos de la Ley de Fundaciones, sin perjuicio de la clasificaciones y referencias que se contienen en otros textos legales, en particular la citada Ley de Contratos del Sector Público (art. 3). Además, la Exposición de Motivos critica que algunos entes públicos mantengan un régimen singular avalado por disposiciones legales y pretende suprimir las especialidades no justificadas.

Pero el articulado del Proyecto se queda a medias en uno y otro propósito, lo que no es casual. La refundición legal es más completa -y no del todo- en el caso de los organismos públicos regulados por la LOFAGE, incluida la eliminación de las agencias estatales (de que tratamos después), y en el caso de fundaciones y consorcios. Pero en lo que se refiere a las autoridades administrativas independientes, a las sociedades mercantiles del sector público estatal y a los fondos sin personalidad, así como a las Universidades, el Proyecto de Ley se remite ampliamente, cuando no por entero, a su legislación propia, de la que se considera supletoria. De otro lado, como es lógico, en todos los casos se recuerda la aplicación de la legislación presupuestaria en los aspectos relativos a presupuestos, contabilidad y control financiero de todas esas entidades, lo que es inevitable.

En cuanto a la pretendida supresión de la consideración de régimen especial de que gozan algunos entes según la legislación vigente (Disposiciones Adicionales $8^{\mathrm{a}}$ a $10^{\mathrm{a}}$ de la LOFAGE), el Proyecto no ha podido culminarla respecto de algunos, como las autoridades portuarias y Puertos del Estado, el Centro Nacional de Inteligencia, las Entidades Gestoras de la Seguridad Social, la Agencia Tributaria, el Banco de España o el FROB (extrañamente definido como autoridad administrativa independiente, calificación que ni cuadra con sus funciones ni le otorga la reciente Ley 11/2015, de 18 de junio, donde se regula), que mantienen su singularidad en las correspondientes disposiciones adicionales del Proyecto (Disposiciones Adicionales $12^{\mathrm{a}}, 13^{\mathrm{a}}$ y $17^{\mathrm{a}} \mathrm{a} 20^{\mathrm{a}}$ ). $\mathrm{Y}$ en caso de que el Proyecto de Ley culminara su tramitación parlamentaria, no cabe descartar que a esa lista se sumen otras. No resulta fácil desconocer la singularidad de esos y otros entes, en lo que se refiere a aspectos como el grado de autonomía funcional, la gestión interna, el régimen de personal o sus retribuciones, por lo que la uniformidad pretendida tiene sus límites.

De otro lado, no se entiende muy bien que se recoja en este Proyecto un precepto sobre las entidades que actúan como medios propios y servicios técnicos de otras que son a su vez entidades adjudicadoras de contratos públicos. No constituyen éstas un nuevo tipo de entidad pública o del sector público a otros efectos, sino que con ello se hace referencia solo a la peculiar situación de instrumentalidad con que algunas entidades del sector público pueden actuar en ocasiones, con el fin de recibir encargos o encomiendas directas sin procedimiento de licitación. Pero, como puso de relieve el Consejo de Estado en su informe sobre el Proyecto de Ley que comentamos, es ésa una definición que interesa nada más a efectos de la legislación de contratos públicos y en ella debe tener 
su acomodo, como hasta ahora sucede. Y como prevé, por cierto, el borrador de anteproyecto de nueva Ley de Contratos del Sector público, que es necesario aprobar en breve para trasponer las nuevas Directivas de contratos públicos de 2014. No parece, sin embargo, que una y otra iniciativa legal se hayan coordinado.

Dicho lo cual, la primera impresión que el Proyecto de Ley sugiere en esta materia es que, en sustancia, se trata de una refundición de otras normas legales, a la que se añaden unas pocas novedades, sobre todo en materia de creación, transformación, fusión y disolución de entes públicos, que es sin duda la mayor preocupación de sus redactores.

\section{IV}

De la nueva clasificación de las entidades que integran el sector público institucional estatal lo que más llama la atención es la supresión de las agencias estatales.

Como es sabido, este tipo de organismo público fue creado por Ley 28/2006, de 18 de julio, impulsada por el Ministro Jordi Sevilla. En realidad, se trata de una variante del género de los organismos autónomos de régimen administrativo. Lo que se pretendía con su introducción era un cambio en el modelo de gestión, basado en la responsabilidad por objetivos, una mayor autonomía para la gestión de los recursos asignados a cada entidad -con presupuestos limitativos por el importe global, aunque estimativos en cuanto a su distribución interna-, la vinculación de una parte de las retribuciones de personal -en porcentaje superior al régimen común-a la productividad y el cumplimiento de objetivos y la selección interna de personal directivo con criterios de mérito y capacidad. Ese modelo empezó a aplicarse inicialmente a ciertos organismos, previstos en el texto de la propia Ley, con la intención de convertirlo paulatinamente en el régimen común al que debían adaptarse los organismos autónomos, con algunas excepciones. Además, según la idea inicial, se deseaba también que en las agencias estatales pudieran integrar ciertos servicios equivalentes de las Comunidades Autónomas (como, por ejemplo, los servicios de meteorología), que participarían en ellas como fórmula de coordinación. Pero, como suele decirse del infierno (sin que quiera con ello comparar), también la política está empedrada de buenos propósitos. Lo cierto es que las Comunidades Autónomas -no solo las de mayoría nacionalista o con gobiernos de color político distinto al que hizo aprobar esa Ley- rechazaron la posibilidad de integración en esas agencias. Y, por otra parte, la aplicación de la Ley, que es tal vez demasiado uniforme en su regulación, no contó con el beneplácito de todas las áreas del propio Gobierno y de los presidentes y gestores de organismos públicos, muchos de los cuales prefirieron mantener el modelo de gestión tradicional. La Ley de Agencias Estatales ha tenido así una aplicación muy limitada, pues son ocho (como recuerda el Consejo de Estado, y no siete, como dice erróneamente la Exposición de Motivos del Proyecto de Ley que comentamos) las que se han constituido desde 2006. Este relativo fracaso y la exigencia de un régimen presupuestario más estricto, con mayor control externo, que ha impuesto la crisis económica y el principio de sostenibilidad financiera, son las razones que ahora se aducen para suprimir esta clase de organismo público. En realidad, la Ley de Agencias Estatales no era una necesidad, pues el modelo de gestión que introdujo podía haberse implantado también a través de los estatutos de los entes en que interesaba. Sin embargo, dicha Ley aporta novedades de interés desde el punto de vista de la gestión pública, que ahora podrían quedar olvidadas, ya que el Proyecto de Ley de Régimen Jurídico del Sector Público se preocupa muy poco del funcionamiento interno de las entidades a que afecta 4 . Su finalidad esencial, como se viene diciendo, no es tanto mejorar ese funcionamiento sino controlar externamente el sector público institucional y reducir el número de entes públicos que o componen.

\section{V}

En cuanto a la lista de entidades que, según el Proyecto de Ley, integran el sector público institucional del Estado, hay ciertas novedades dignas de mención y de comentario.

El Proyecto de Ley mantiene las dos categorías básicas establecidas por la LOFAGE, es decir, los organismos autónomos y las entidades públicas empresariales. Pero la definición de unos y otras sufre un cambio importante. Conforme a la LOFAGE, los organismos autónomos realizan a actividades "de fomento, prestacionales o de gestión de servicios públicos" (art. 45.1) y se rigen esencialmente por el Derecho administrativo, tanto en su organización como en sus actividades. Las entidades públicas empresariales realizan "actividades prestacionales, la gestión de servicios o la producción de bienes de interés público susceptibles de contraprestación” (art. 53.1) y se rigen básicamente por el Derecho privado, salvo en lo que se refiere a la formación de la voluntad de sus órganos y al ejercicio de las potestades administrativas que se les atribuyan. El esquema de la LOFAGE es, pues, sencillo, ya que la diferencia se funda en el tipo de actividad que realiza cada entidad y, sobre todo, si son actividades susceptibles o no de contraprestación, de lo que se sigue el régimen público o privado aplicable básicamente a esas acti-

4 No deja de ser contradictorio que, al tiempo que se preparaba el anteproyecto de ley que comentamos, el Gobierno haya elaborado y finalmente aprobado por Real Decreto 461/2015, de 5 de junio, el Estatuto de la Agencia Española de Protección de la Salud en el Deporte, que aplica la Ley $28 / 2006$, lo que indica que el modelo de ésta sigue siendo de utilidad en algunos casos. 
vidades. No obstante esa diferencia no es rígida, ya que, mientras que a las entidades empresariales se les pueden asignar potestades administrativas (art. 53.2), a ejercer con sujeción al Derecho administrativo, se prevé que los organismos autónomos pueden ser autorizados a obtener ingresos propios (art. 45.2), lo que supone algún tipo de contraprestación, normalmente mediante tarifas o precios públicos.

Ahora el Proyecto de Ley que comentamos introduce otro criterio distintivo. Los organismos autónomos pueden destinarse también a la producción de bienes de interés público susceptibles de contraprestación (art. 98.1), mientras que las entidades públicas empresariales pueden realizar ese mismo tipo de actividades y otras prestacionales y de gestión de servicios, pero, "se financian mayoritariamente con ingresos de mercado" (art. 103.1). Y entiende el Proyecto que lo hacen "cuando tengan la consideración de productor de mercado de acuerdo con el Sistema Europeo de Cuentas” (art. 107.3), algo que queda reflejado en la clasificación que se haga de las entidades a efectos de la contabilidad nacional. Quiere eso decir que solo cumplen ese requisito si son entidades que venden sus productos o servicios a precios de mercado y financian con ello, de manera sostenida durante varios años, al menos el 50 por 100 de los costes de producción, de conformidad con el Reglamento (UE) 549/2013, del Parlamento Europeo y del Consejo, de 21 de mayo de 2013, que regula el denominado SEC 10. Siendo así, los casos en que un organismo público puede ser calificado como entidad pública empresarial se estrechan, de manera que, si el Proyecto de Ley fuese aprobado y con su actual redacción en este punto, quizá algunas de las actuales entidades públicas empresariales deberían reconvertirse en organismo autónomo. Esta consecuencia es fruto de la preferencia, que el Proyecto de Ley no oculta, por la aplicación del régimen administrativo a la mayoría de las entidades públicas, limitando al máximo la aplicación directa del Derecho privado.

\section{VI}

Por otra parte, el Proyecto de Ley hace mención separada de las autoridades administrativas independientes, a lo que nada hay que objetar, dadas sus relevantes peculiaridades. Ya se ha dicho, no obstante, que el Proyecto de Ley apenas las regula, ya que se remite a su legislación propia, entendiendo supletoriamente aplicable el régimen de los organismos autónomos, de los que en realidad constituyen un subtipo en términos orgánicos. Ahora bien, resulta más que preocupante desacertada la definición que el Proyecto da de esas autoridades independientes como las que "tienen atribuidas funciones de regulación o supervisión de carácter externo sobre un determinado sector o actividad económica..." (art. 109.1). Aparte de lo impreciso de la mención al "carácter externo" -externo a la Administración General del Estado, parece querer decir, pues no va a ser externo al propio mercado regulado-, lo cierto es que hay autoridades administrativas independientes, reconocidas expresa o implícitamente como tales por su legislación propia, que no regulan o supervisan sectores económicos, sino que tienen otras funciones relativas a la protección de algunos derechos fundamentales u otros bienes de interés público. Es el caso de la Agencia de Protección de Datos o el reciente Consejo de Transparencia y Buen Gobierno y, en otro orden de cosas, del Consejo de Seguridad Nuclear. Como no parece creíble que los autores del Proyecto de Ley hayan querido apear a estas entidades de su tratamiento de autoridades independientes, hay que concluir que la definición que se da de éstas constituye un error -otro más- de concepto, debido a la mala técnica legislativa del texto.

Sorprende también que se añada que las autoridades administrativas independientes actúan "con independencia de cualquier interés empresarial o comercial" (art. 109.2). Este añadido es confuso, pues esa independencia de actuación respecto de intereses empresariales o comerciales -obviamente privados- es predicable de toda la Administración Pública, que por definición actúa exclusivamente al servicio de los intereses generales (art. 103.1 CE), y no solo de las autoridades administrativas independientes. Lo que caracteriza a éstas es su "independencia" -rectius, su mayor autonomía funcional- respecto del Gobierno, con el fin de evitar interferencias políticas espurias. Esto es lo que se debería haber subrayado. Pero al apuntar a otro tipo de independencia, parece como si el Proyecto de Ley minusvalorara lo que sustancial a ese tipo de autoridades.

\section{VII}

Por lo que se refiere a las entidades privadas del sector público o entidades de derecho privado vinculadas o dependientes de las Administraciones Públicas, como se denominan en el artículo 2.2.b), el Proyecto de Ley incluye las sociedades mercantiles estatales y las fundaciones del sector público (art. 84.1).

Dejando de lado las denominaciones -que es lo que menos importa- y las escasas novedades de la regulación de unas y otras entidades, no puede dejar de comentarse que el Proyecto de Ley reconoce que las entidades privadas del sector público pueden ejercer "potestades administrativas". Así se deduce del artículo 2.2.b) (y del mismo precepto del Proyecto de Ley del Procedimiento Administrativo Común de las Administraciones Públicas). Con ello parece quebrarse la regla en contrario hasta ahora claramente establecida por la Disposición Adicional $12^{\text {a }}$ de la LOFAGE, según la cual las sociedades mercantiles estatales "en ningún caso podrán disponer de facultades que 
impliquen el ejercicio de autoridad pública". Sin embargo, esta misma regla se recoge textualmente en el artículo 113 del Proyecto de Ley, con el añadido de "sin perjuicio de que excepcionalmente la ley pueda atribuirle [a una sociedad mercantil estatal] el ejercicio de potestades administrativas". Por lo que se refiere a las fundaciones del sector público, el artículo 128.2 del Proyecto de Ley reitera lo que ya establece el artículo 46.1 de la vigente Ley de Fundaciones, esto es, que "no podrán ejercer potestades públicas". Con todos estos preceptos el Proyecto de Ley genera una gran confusión, ¿A qué "potestades administrativas" se refiere, que sean distintas de las "facultades que impliquen ejercicio de autoridad”? ¿Cuál es la diferencia -si la hay- entre las "potestades administrativas" que excepcionalmente podrían ejercer los entes privados del sector público y las "potestades públicas” que en ningún caso pueden ejercer las fundaciones?

Todo esta cuestión requiere mucha claridad, pues si la redacción del Proyecto se mantuviera como está y se convirtiera en ley, por de pronto se plantearía un problema peliagudo de interpretación y es de temer que de la incertidumbre se puedan derivar consecuencias no previstas en la aplicación de la Ley por algunos operadores.

El ejercicio de potestades públicas, que son aquellas que no puede realizar ningún particular, ya que son inherentes al poder público y se ejercen en relaciones de supremacía, está y ha estado siempre reservado a las Administraciones y entidades de derecho público, pues a ellas y solo a ellas se les aplica la generalidad de las garantías del derecho público, desde el principio de vinculación positiva a la ley, pasando por la garantía del procedimiento contradictorio, hasta el régimen de recursos, amén de la imparcialidad que garantiza el estatuto de las autoridades y funcionarios públicos que las ejercen. No sólo eso sino que las entidades privadas que forman parte del sector público tienen unos criterios distintos de funcionamiento. En particular las sociedades mercantiles operan en el tráfico privado y, como es natural, con ánimo de lucro, aunque dependan de un Gobierno o Administración Pública. Tanto ellas como las fundaciones pueden integrar en sus órganos rectores o de administración a personas físicas privadas, que no están vinculadas a la tutela de los intereses públicos. Por eso, atribuir en abstracto la posibilidad de que entidades del sector privado, aun dependientes o controladas por una Administración o ente público, puedan ejercer ese tipo de potestades, pone en riesgo de quiebra el sistema de garantías de Derecho administrativo.

Quizá los autores del Proyecto no han querido expresar una idea semejante. Pero es difícil adivinar la razón de la confusión. Quizá han considerado que una sociedad o del sector público ejerce una potestad administrativa cuando adjudica un contrato del sector público, pues tal adjudicación está sujeta a principios y requisitos de procedimiento propios del Derecho público. O bien que lo mismo sucede si una sociedad o fundación pública otorga ayudas o subvenciones con cargo a sus presupuestos o actuando como entidad colaboradora de la Administración. 0 han entendido que ejercen algún tipo de potestad pública cuando colaboran con una Administración como medio propio o servicio técnico de la misma. Pero en todos estos casos es impropio decir que ejercen potestades administrativas. Lo que sucede es que a ese tipo de actividades, de por sí privadas, ya que puede realizarlas también un particular o empresa privada, se les aplican ciertas garantías de derecho público cuando se ejercen por entidades del sector público y con recursos públicos: transparencia, igualdad y no discriminación, motivación o justificación de la decisiones, a veces incluso una posibilidad de recurso o reclamación ante la Administración de tutela. Pero no es lo mismo tener que respetar ciertas garantías de derecho público en sus relaciones con los particulares que ejercer potestades públicas, lo que significa que se sitúan en posición de supremacía. Pues en todos esos casos a que nos hemos referido y otros semejantes, como en el de las encomiendas de gestión a medios propios, las entidades de derecho privado no dictan actos administrativos, ni se someten al régimen general de recursos. Hay quizá algún caso en que es así, por razones históricas y pragmáticas, como el de la relación jurídica que mantiene la Sociedad Estatal Correos y Telégrafos con aquellos de sus empleados que, en virtud de pacto sindical, han mantenido su status de funcionarios públicos que tenían antes de que el antiguo organismo público del mismo nombre se transformara en sociedad mercantil. Pero esta singular situación, a extinguir con el paso del tiempo, no justifica que se admita una posibilidad general y de contornos imprecisos de atribuir por ley potestades administrativas a entidades que no han sido pensadas ni creadas para ejercerlas. Esperemos que, de ver la luz como Ley, el texto actual del Proyecto se aclare y se matice también en este punto.

Por otra parte y por lo que se refiere a las sociedades mercantiles estatales, el Proyecto de Ley no establece una regulación completa, sino que mantiene la de la Ley de Patrimonio de las Administraciones Públicas (arts. 166 a 182), a la que se remite y en la que introduce solo modificaciones formales (Disposición Final $2^{\circ}$ ). No se ha querido sustituir ni cambiar esta otra regulación legal de esas sociedades, que es mucho más completa. Ni siquiera se han recogido en el Proyecto de Ley las disposiciones particulares sobre las sociedades en las que el capital es público en su totalidad, que en realidad constituyen una variante específica del género. Solo se viene a cambiar, indirectamente, el régimen de responsabilidad de los administradores de las sociedades estatales designados por la Administración, cuestión a la que nos referimos más adelante.

Tampoco hay novedades de relieve en el régimen jurídico de las fundaciones del sector público (arts. 128 a 
136), salvo las reglas para determinar a qué Administración Pública están adscritas cuando participen varias de ellas en la fundación (art. 129), que se inspiran en las establecidas para los consorcios y tienen como éstas carácter básico. A las normas sobre su creación y disolución y la responsabilidad de los miembros de los patronatos nos referimos luego.

\section{VIII}

En fin, por no extendernos, en lo que se refiere a los consorcios el Proyecto de Ley (arts. 118 a 127) asume prácticamente la regulación legal de carácter básico ya existente, en particular la contenida en la Disposición Adicional $20^{a}$ de la Ley 30/1992 (LRJPAC), añadida por la Ley 27/2013, de 27 de noviembre (LRSAL) y en la Ley 15/2014, de 16 de septiembre, de racionalización del sector público y otras medidas de reforma administrativa. También se incluye una norma (art. 121) para permitir con mayor facilidad que los consorcios cuenten con personal propio y no solo con el que les transfieran las Administraciones que participen en él, corrigiendo en parte una norma (muy poco realista) introducida por la LRSAL. Por cierto, esa corrección legal ya es ley, pues se ha incluido como Disposición Final $2^{a}$ de la Ley Orgánica 6/2015, de 12 de junio.

$Y$ en lo que se refiere a los fondos sin personalidad jurídica, aparte unas breves reglas sobre su creación y extinción, el Proyecto (art. 137 a 139) se remite en bloque a lo que disponga la Ley de creación, a la legislación presupuestaria y a la legislación administrativa, que se aplica supletoriamente. En realidad, incluir esta figura dentro del llamado sector público institucional no parece muy justificado ni se explica en la Exposición de Motivos del Proyecto.

\section{IX}

Dicho lo anterior y por lo que se refiere al régimen jurídico de las entidades que componen el sector público institucional del Estado, las novedades del Proyecto de Ley son escasas, pues, como se ha dicho, se trata más bien de una refundición de textos legales varios. Lo que más destaca es el énfasis que se pone en los instrumentos para reducir o limitar esas entidades y para reordenar el conjunto del sector público. Pues, junto a aquella labor de refundición, el leit motiv de la reforma legal, por lo que se refiere al sector público institucional, no es otro que el de controlar su expansión o su dimensión, desde el Ministerio de Hacienda y Administraciones Públicas, en atención a los principios de sostenibilidad financiera y control de gasto público.

A tal efecto se introduce el sistema de supervisión continua, que para los entes del sector público estatal se desarrolla en el artículo 85.3 del Proyecto de Ley. Esa novedad debe subrayarse positivamente, en la medida en que persigue no mantener por inercia burocrática o, como suele suceder, por intereses políticos o corporativos, entidades que han dejado de tener justificación, sea por un cambio de circunstancias -entre ellas el cambio de políticas públicas-, por incumplimiento o defectuoso cumplimiento de sus fines o por razones de sostenibilidad financiera. Este tipo de supervisión, existente en otros países, es imprescindible y debería haber sido introducido hace tiempo, ya por Gobiernos anteriores que (puedo dar fe de ello) tuvieron sobre la mesa informes o propuestas en el mismo sentido. Es de desear incluso que si el Proyecto de Ley que comentamos decayera al término de la legislatura, al menos esta novedad -y también otras- se replanteara de nuevo cuanto antes, en su caso, como modificación parcial de la legislación vigente. Dicho sea sin perjuicio de que es un tipo de control adecuado sobre los entes puramente instrumentales, pero no si se extiende a las autoridades administrativas independientes, ya que podría utilizarse en menoscabo de su necesaria autonomía frente al Gobierno. Así lo subraya en su informe el Consejo de Estado.

En el mismo sentido destaca la regulación, muy detallada, de la transformación de las entidades del sector público estatal en otras de distinto tipo, que se contiene en el artículo 87 del Proyecto. De esta regulación conviene apuntar varios aspectos. En primer lugar, se trata de facilitar este tipo de decisiones, en cuanto que pueden llevarse a cabo por norma reglamentaria, aunque ello signifique modificar la ley de creación de la entidad afectada. Este tipo de deslegalización no se prevé en la LOFAGE para la modificación de los organismos públicos que implique el cambio del tipo de organismo (art. 63), pues la LOFAGE exige siempre ley en este y otros casos de modificación y refundición de organismos públicos. Ahora bien, si la transformación tiene una finalidad "privatizadora" del régimen de la entidad o de "huida del Derecho administrativo" -tanto si un organismo autónomo se transforma en entidad pública empresarial, sociedad estatal o fundación o si una entidad pública empresarial se transforma en sociedad o fundación- se exigen una serie de garantías: memoria justificativa, análisis de eficiencia, análisis de los efectos sobre el personal y un informe preceptivo de la IGAE sobre todo ello. Por otra parte, el Proyecto de Ley se preocupa de precisar los efectos de la transformación de un tipo de organismo en otro en materia de personal, cuestión que a menudo es problemática y conflictiva. Si la transformación conlleva la integración de personal en la Administración General del Estado, ello debe hacerse conforme a los procedimientos de movilidad previstos 
en la legislación de función pública o laboral; el personal de la entidad transformada conserva los derechos y obligaciones que les correspondan en virtud de la normativa que les sea aplicable; en ningún caso la transformación supone de por sí atribuir al personal laboral afectado la condición de funcionario público, ni legitima procesos de funcionarización, de manera que el personal laboral que ejerza funciones reservadas a funcionarios se integraría con la condición de "a extinguir"; en fin, de la transformación no puede derivarse incremento alguno de la masa salarial. O sea, todo tipo de cautelas para evitar el aumento del gasto público de personal.

Estas normas de general aplicación a todos los entes del sector público institucional estatal se complementan con las que se establece para cada tipo de entidad en cuanto a la creación, fusión, disolución y liquidación.

La creación de nuevos organismos públicos -ya sean organismos autónomos o entidades públicas empresariales- se somete a reglas y controles más estrictos de los hasta ahora existentes. No basa ya con la exigencia de ley de creación. Ley que, por cierto, también se requiere para crear autoridades administrativas independientes, como es natural, y para crear o asumir el control de una fundación del sector público, crear fondos sin personalidad jurídica -esto es ya más extraño- e incluso para autorizar la participación de la Administración del Estado y sus organismos públicos en un consorcio. Solo para la creación de sociedades mercantiles estatales o para adquirir de manera sobrevenida la mayoría del capital en una sociedad basta la autorización del Consejo de Ministros.

Además, en el caso de los organismos públicos (y de las fundaciones), el Proyecto de Ley (art. 92) detalla minuciosamente el contenido del Plan de Actuación que debe acompañar al correspondiente anteproyecto de ley de creación, en el que se deben justificar, entre otros extremos, las razones de la necesidad del nuevo ente, la suficiencia de la dotación económica inicial y la sostenibilidad futura, la suficiencia e idoneidad de los objetivos del organismo y los indicadores para medirlo, el programa plurianual estratégico, las previsiones en materia de personal y su coste, etc. Sobre todo ello debe acompañarse informe preceptivo y favorable del Ministerio de Hacienda y Administraciones Públicas, que se reserva así el control último de creación de nuevas entidades.

El plan de actuación, por lo demás, debe ser actualizado anualmente, con revisión cada tres años del programa estratégico. Y, a falta de actualización en plazo, por causa imputable al organismo, llevaría aparejada la paralización de las transferencias que deban realizarse a su favor con cargo a los Presupuestos Generales del Estado, salvo que el Consejo de Ministros adoptara otra decisión (lo que es previsible).

Por lo que se refiere a las sociedades mercantiles estatales, su creación o la asunción sobrevenida de su control mayoritario por el Estado debe acordarse previa justificación de las razones que aconsejan esas decisiones, de que no se incurre con ello en duplicidades dentro del sector público, de que resulta la opción más eficiente frente a la creación de un organismo público u otras alternativas, y previa determinación de sus objetivos anuales y los indicadores para medirlos (art. 114). Todo ello debe ser objeto de informe preceptivo y favorable, es decir, vinculante por parte del Ministerio de Hacienda y Administraciones Públicas o la IGAE.

Mientras que el Proyecto de Ley acumula cautelas para el caso de creación de nuevos entes, facilita en cambio su fusión, sea para formar un organismo nuevo o para ser absorbido por otro ya existente (art. 94). Esta fusión, que debe ser de organismos públicos del mismo tipo o naturaleza, puede llevarse a cabo siempre por norma reglamentaria, aunque ello suponga modificar la ley de creación, algo que la LOFAGE contempla solo en ciertos casos. La mayor novedad, en cualquier caso, es que la norma de fusión debe ir acompañada de un plan de redimensionamiento de estructuras, inmuebles, personal y recursos, que demuestre el ahorro que se conseguirá con la fusión. El objetivo es, pues, también en este caso la reducción del gasto público. El plan de redimensionamiento puede incluir la integración en un fondo sin personalidad jurídica (un "fondo malo", diríamos) de las obligaciones, bienes y derechos liquidables de los organismos que se extinguen con la fusión y están en situación de desequilibrio financiero. Dicho plan debe ser informado preceptivamente por la ICAE y aprobado por los organismos que se fusionan, si se integran en uno nuevo, o por el organismo absorbente. Por supuesto, en caso de fusión se aplican las mismas reglas que en el supuesto de transformación en materia de personal: posible integración de personal en la Administración General del Estado; reconocimiento de los derechos y deberes que correspondan al personal integrado según la legislación aplicable, rechazo expreso de la funcionarización de personal laboral, no incremento de la masa salarial. La fusión que el Proyecto contempla tiene, pues, por objetivo prioritario conseguir un ahorro del gasto público y no una mejora en la organización o prestación de los servicios de los entes fusionados.

Con parecido lujo de detalle y la misma intención de facilitar y agilizar los procedimientos, se regula en el Proyecto la disolución y liquidación de organismos públicos estatales. En comparación con la LOFAGE, se amplían las causas legales de extinción, para incluir los supuestos de incumplimiento de los fines para que fue creado el organismo o falta de idoneidad para conseguirlos, que se deduzca del control de eficacia o de la supervisión continua. También es causa de disolución que el organismo se encuentre en situación de desequilibrio presupuestario durante dos ejercicios consecutivos. Pero en este último caso procede en un primer momento aprobar un plan de 
reequilibrio y solo si en otros dos ejercicios no se corrige el desequilibrio se podrá disolver el organismo, salvo que el Consejo de Ministros acuerde prorrogar el plan de corrección.

Por lo demás, el Proyecto regula de manera minuciosa el procedimiento de disolución y la liquidación, fijando plazos muy breves (y poco creíbles), bien para que el máximo responsable del organismo comunique la existencia de causa de disolución, bien para que el Consejo de Ministros la acuerde, con la drástica consecuencia de que el transcurso de unos u otros plazos supone la disolución automática del organismo, ope legis, sin que el mismo pueda realizar ningún acto jurídico más, salvo los estrictamente necesarios para su extinción y liquidación.

En definitiva, facilidades para la extinción de organismos públicos, por una u otra vía. El mismo régimen es aplicable a las fundaciones del sector público, conforme al artículo 136 del Proyecto. Y, por lo que se refiere a los consorcios, lo que se hace es recoger las normas sobre disolución y sobre separación de los miembros del mismo ya establecidas (o adelantadas) en la Ley 15/2014, de 16 de septiembre, de racionalización del sector público y otras medidas de reforma administrativa, normas que pretenden igualmente regular una forma ordenada y ágil de extinción o bien de abandono de los consorcios por alguna de las Administraciones consorciadas, en especial la del Estado. En todos los casos, la disolución no requiere ser aprobada por ley sino, en su caso, por norma reglamentaria.

\section{$\mathrm{X}$}

Otra novedad viene constituida por la obligación de que los organismos públicos estatales incluyan en su norma constitutiva la gestión compartida de los servicios comunes, entendiendo por tales los de gestión de bienes inmuebles, sistemas de información y comunicación, asistencia jurídica, contabilidad y gestión financiera, publicaciones y contratación pública (art. 95 del Proyecto). Dicha gestión compartida sería la regla general, salvo excepción justificada en razones de seguridad nacional, o de autonomía de gestión o independencia del organismo. La gestión se compartiría normalmente con los servicios comunes del Ministerio de adscripción, aunque el Proyecto de Ley prevé que pueda organizarse de otra forma por el Ministerio de Hacienda o por un organismo público vinculado o dependiente del mismo (que no se adivina cuál pudiera ser) o por otro organismo público del que dependa o al que esté vinculado el organismo afectado. Según la Disposición Adicional $5^{\mathrm{a}}$ la gestión compartida debería adoptarse desde la entrada en vigor de la nueva Ley, salvo que se justifique en una memoria dirigida al Ministerio de Hacienda y Administraciones Públicas que concurre alguna de las circunstancias que avalan legalmente la excepción.

Pero en caso de aprobarse el Proyecto de Ley con esa previsión, no será fácil ponerla en práctica de manera rigurosa, ya que cada organismo procurará organizar internamente esos servicios antes de que queden confiados a servicios y funcionarios que no se sitúan en su línea jerárquica. En cualquier caso, si dicha regla se impusiera efectivamente como general, en la práctica constituiría un motivo para desincentivar la creación de nuevos organismos. Sobre todo porque, indirecta o implícitamente, supone reforzar el control externo por parte de la Administración General, siendo así que lo que se busca precisamente con la descentralización funcional, justificadamente o no, es una mayor autonomía de gestión.

\section{$\mathrm{XI}$}

Ya se ha dicho que el Proyecto de Ley no persigue directamente mejorar el funcionamiento interno de cada organismo o ente del sector público institucional. Por eso en este orden no hay prácticamente novedades. Muy al contrario, es significativo que la ley que con más énfasis pretendió introducirlas, que fue la Ley de Agencias Estatales, quede derogada sin más y no, como otras, refundida en este texto legal en proyecto. Nada de dicha Ley se mantiene en éste, pese a que algunos aspectos hubieran merecido mayor atención.

Particularmente notorio es que el Proyecto de Ley no contenga ningún avance -y apenas normas- en materia de gestión de personal y empleo público. Este sector público institucional es, quizá, más proclive que otras áreas de la Administración a introducir cambios que flexibilicen y agilicen la gestión y que refuercen la profesionalidad del personal, empezando por el personal directivo. Pero nada de ello se contempla en aquél. Aparte algunas vaguedades y el recordatorio de los límites retributivos que impuso el Real Decreto 451/2012, de 5 de marzo (al que el Proyecto se remite expresamente, lo que no deja de ser un nuevo defecto de técnica legislativa, pues una ley llamada a perdurar no debería remitirse a concretos textos reglamentarios contingentes), no hay nada relativo al régimen del personal directivo profesional de los entes públicos, lo que demuestra una vez más el nulo interés del actual Gobierno por desarrollar y aplicar el artículo 13 del Estatuto Básico del Empleado Público. Y salvo alguna breve referencia a la vinculación del complemento de productividad con el cumplimiento de los objetivos de cada organismo, como contenido necesario de sus planes de actuación, nada se apunta sobre la evaluación del personal u otros instrumentos de gestión de recursos humanos. 
Eso sí, el Proyecto de Ley se ha preocupado de exonerar de responsabilidad directa a los empleados públicos que sean designados como miembros de los consejos de administración de las sociedades mercantiles estatales en el ejercicio de esa función (art. 115) y a los que se designen para formar parte de los patronatos de las fundaciones del sector público estatal (art. 135). La responsabilidad en que puedan incurrir como tales "será directamente asumida por la Administración General del Estado", sin perjuicio de que ésta pueda repetir contra el empleado público miembro de unos u otros órganos si hubieran actuado con dolo o culpa o negligencia grave, "conforme a lo previsto en las leyes administrativas en materia de responsabilidad patrimonial".

Con ello se persigue aplicar el régimen de responsabilidad patrimonial de las autoridades y empleados públicos regulado en la legislación administrativa (art. 144 de la Ley 30/1992) a quienes sean designados por la Administración estatal para dirigir una entidad privada del sector público. En la medida en que dicho régimen de responsabilidad patrimonial de autoridades y funcionarios implica un privilegio, sea porque quedan exentos de responsabilidad directa por sus actos, sea porque solo se puede atribuirles esa responsabilidad mediante una acción de regreso en caso de dolo o culpa grave -que raramente se constata y se concreta en la práctica- de lo que se trata es de extender dicho privilegio. En tal sentido puede pensarse que, desde un punto de vista sustantivo, no es distinta la situación de un funcionario o empleado público que es designado para formar parte del consejo de administración de un organismo autónomo o de una entidad pública empresarial, a los que hoy se aplica ya el citado artículo 144 de la LRJPAC, que la de que tienen los que forman parte de órganos semejantes, pero en una sociedad o fundación del sector público.

Sin embargo, la solución adoptada, aparte de algunos problemas conceptuales -cuál es el régimen aplicable a quienes son designados por la Administración para el consejo de administración de una sociedad o para el patronato de una fundación, pero no son “empleados públicos?- suscita ciertas dudas esenciales. La primera es determinar si la responsabilidad que se atribuye directamente a la Administración General del Estado en estos casos es la que se regula en la legislación administrativa, en el Código Civil o en el Texto Refundido de la Ley de Sociedades de Capital (art. 236 a 241 bis). La cuestión no es baladí, ya que los títulos de imputación de la responsabilidad son distintos en cada caso: funcionamiento normal o anormal del servicio en el primer caso, dolo o culpa en el segundo. Tampoco queda claro qué tipo de acción se podrá instar en tales supuestos: la acción de responsabilidad patrimonial de la Administración regulada en la LRJPAC o las acciones sociales o individuales previstas en el Texto Refundido de la Ley de Sociedades de Capital (art. 238 y 241). No solo la competencia y el orden jurisdiccional varían en uno y otro caso. También los sujetos legitimados y el plazo de prescripción (un año o cuatro).

De otra parte, el régimen administrativo de responsabilidad solo cubre a los "empleados públicos" que sean designados por la Administración General del Estado en los consejos de administración y patronatos, pero no al resto de los consejeros o patronos. Se crea así una diferencia de trato no claramente justificada entre unos y otros. Además, siendo la responsabilidad de todos los consejeros solidaria (art. 237 del Texto Refundido de la Ley de Sociedades de Capital) se plantea el dilema de si, como tal, se puede exigir directamente de la Administración.

En fin, resulta criticable que una norma de carácter básico, como es la del artículo 144 de la ley 30/1992, se extienda a supuestos para los que no estaba prevista, pero solo si las sociedades o fundaciones son estatales -no dependientes de Comunidades Autónomas o Entidades Locales-, ya que las del Proyecto de Ley que comentamos no tendrían carácter básico.

Es obvio que los redactores de éste no han tenido en cuenta todos estos problemas y efectos colaterales de la norma. De manera más lógica, el vigente artículo 179 de la Ley de Patrimonio de las Administraciones Públicas exonera de responsabilidad personal a los consejeros de las sociedades del sector público cuando cumplan instrucciones que les imparta la Administración que les designó. Pero ello sin alterar el régimen jurídico de la responsabilidad de los administradores de sociedades y fundaciones, que debe seguir siendo de derecho privado. Así lo señala igualmente, de manera muy crítica, el dictamen del Consejo de Estado sobre el Proyecto de Ley.

\section{XIII}

En conclusión, también por lo que se refiere a la regulación del sector público institucional, la reforma que se plantea, no obstante las buenas intenciones y algunos aspectos positivos, es una reforma precipitada, técnicamente muy defectuosa y que decepciona por su anómala sistemática y la ausencia de novedades en cuanto al régimen interno de los entes públicos que regula. Por eso lo mejor es que el Proyecto de Ley de Régimen Jurídico del Sector Público se retire por el Gobierno o no llegue a aprobarse y que se aborden las reformas necesarias con más sosiego y con mayor cuidado, teniendo en cuenta, entre otras, las observaciones formuladas por el Consejo de Estado. 